\title{
ELABORATION OF PLANIMETRIC MODEL OF OPEN PIT WITH MULTIPLE BENCHS THROUGH THE CONVENTIONAL METHODOLOGY AND THE USE OF UNMANNED AERIAL VEHICLES (UAV)
}

\author{
João Manoel Lourenço Correia Neto ' \\ Jorge Luiz Valença Mariz ${ }^{2}$ \\ Júlio César de Souza ' \\ Silas Leonardo Dias Vasconcelos ' \\ Suelen Silva Rocha'
}

\begin{abstract}
When comparing topographic models generated through conventional methodology, which uses total station, with the models generated through UAV flight, aerial photogrammetry allows a larger volume of data that, through appropriate adjustment, provides reliable information of high precision, in addition to higher quality in the presentation of the product. The aim of this work is to compare the planimetric models produced with the purpose of verifying the progress of exploitation in multiple granite benches through the two methodologies mentioned. Hence, a survey was performed using the total station followed by the production of a model. Simultaneously, flights with different parameters were executed in order to select the Digital Surface Model (DSM) with the lowest global error, followed by the construction of another model, validated through the altimetric comparison in several points of this with the height measured in the field. Finally, it was possible to compare the two products from the theoretical width of the slopes and the one presented by the models between the foot and the projection of the crest of several points of the slopes, allowing concluding that the model generated using UAV presents greater coherence and reliability.
\end{abstract}

Keywords: Open pit mining; Mine planning; Terrain modeling; UAV.

\section{ELABORAÇÃO DE MODELO PLANIMÉTRICO DE CAVA DE BANCADAS MÚLTIPLAS ATRAVÉS DA METODOLOGIA CONVENCIONAL E DO USO DE VEÍCULOS AÉREOS NÃO TRIPULADOS (VANT)}

\section{Resumo}

Quando comparados modelos topográficos gerados através da metodologia convencional, que utiliza estação total, com modelos gerados através de um voo de VANT, a aerofotogrametria permite uma coleta maior de dados que, através de ajuste adequado, fornece informações confiáveis de alta precisão e maior qualidade na apresentação do produto. Este trabalho tem como objetivo efetuar a comparação dos modelos planimétricos produzidos com o intuito de verificar o avanço de uma lavra em bancadas múltiplas de granito através das duas metodologias citadas. Para tal foi executado um levantamento através do uso de estação total seguido da produção de um modelo. Simultaneamente, foram executados voos com distintos parâmetros para que fosse selecionado o Modelo Digital de Superfície (MDS) com menor erro global, seguido da construção de outro modelo, validado através da comparação altimétrica em diversos pontos deste com a altura aferida em campo através de trena. Finalmente, foi possível comparar os dois produtos a partir da largura teórica dos taludes e a apresentada pelos modelos entre o pé e a projeção da crista de diversos pontos dos taludes, permitindo concluir que o modelo gerado através do uso de VANT apresenta maior coerência e confiabilidade.

Palavras-chave: Lavra a céu aberto; Planejamento de lavra; Modelagem de terreno; VANT.

'Universidade Federal de Pernambuco - UFPE, Recife, PE, Brasil. E-mail: joao.mlcorreia@hotmail.com

${ }^{2}$ Programa de Pós-graduação em Engenharia de Minas, Metalúrgica e de Materiais, Universidade Federal do Rio Grande do Sul - UFRGS, Porto Alegre, RS, Brasil 


\section{INTRODUCTION}

The interest in unmanned aerial vehicles (UAVs) has increased rapidly, mainly due to factors such as the ability to fly over hard-to-reach or hostile areas, low cost and ease of operation, low risk of accidents involving people and use in confined spaces with low flight altitude. Such qualities make this technology attractive for mining purposes, where concerns about staff safety are increasing and the need to reduce costs and time in service delivery is pressing. In addition, the use of UAVs can assist in the supervision of the mining exploitation progress and tailings dams by the competent authorities, by the generation of planimetric and flood maps $[1,2]$.

Photogrammetry is the science of obtaining reliable information about the properties of surfaces and objects without physical contact with the objects, and of measuring and interpreting this information. One objective of photogrammetry is the reduction of field work in surveying coordinates of one or more objects and the time to obtain such information. Among its many applications, one of the most important areas is the open pit mining monitoring, as it allows the execution of land modeling with high precision and speed, providing data for the updating and sequencing of mining [3-5].

The updating of mining exploitation progress should be carried out regularly to ensure the reconciliation between the planned model and the execution, and there are different ways to execute this monitoring. However, a conventional topographic survey (use of total station and targets) is an activity that takes time and can be executed without proper accuracy. Through aerial photogrammetry using UAV's, large areas (even those difficult to access) can be determined in short time, where detailed information about the terrain is collected, which makes this method ideal for the collection of routine data. These vehicles equipped with digital cameras are capable of generating high resolution images that can be processed in software to produce Orthomosaics and Digital Surface Models (DSM) [6].

In this context, the purpose of this study is to compare the topographic planimetric models generated through the conventional methodology, which uses total station and targets to collect sparse points along the terrain, with the product of a UAV flight and later modeling of the photos. The flights with UAV were performed at varied altitudes and using different applications (apps), from which it was possible to evaluate and select the model that presented the most accurate result considering the smallest global error in the DSM. Afterwards the validation of the altimetry of the DSM was performed by comparing the height of some points of the bench in the field with the use of measuring tape, thus verifying the reliability of the model. Finally, from the validated DSM, a planimetric model was produced and its results were compared with the product of the conventional methodology from the theoretical slope width and the one presented by the models between the foot and the projection of the crest of several points of the slopes.

\section{METHODOLOGY}

The area selected for the study was the Pedreira Esperança's mine pit, located on the margins of the BR-232, Km 39, countryside of Vitória de Santo Antão, state of Pernambuco, a mining enterprise that operates the exploitation of a granite through open pit multiple benches. The coordinate system used throughout the study was Universal Transverse Mercator (UTM), Datum SIRGAS 2000/zone 25S (EPSG: 31985) and the UAV used to perform this work was a Phantom 4 Advanced.

\section{I Conventional Planimetric Survey}

In order to carry out this survey, a topography team experienced in this kind of work was hired. Initially, in order to allow the correct positioning of the collected points, the georeferencing of three points was performed with a high precision Global Positioning System - GPS (Topcon Hiper II Geodetic Receiver). The coordinates of these points were used as reference to the other points obtained. The team then walked through the roads and the berms of the pit, collecting points in pertinent places to determine the crests and feet of the slopes. After the collection, the obtained points were plotted in CAD (Computer-Aided Design) software, in which the planimetric model of the mine pit was constructed.

\subsection{Planimetric Survey Through UAV}

Similar to the conventional method, in this methodology it is also necessary to obtain reference points, using in this case eight points, a predetermined quantity taking into account the distribution throughout the pit and the differences of altitudes of each berm, as shown in the Figure I. These points, called control points, here named Base, P2, P3, P4, P5, P6, P7 and P8, were obtained through a precision GPS model Topcon Hiper II Geodetic Receiver, in which the base remained capturing the signals from the satellites for about 3 (three) hours and the hover remained at each point for 10 (ten) minutes.

After the coordinates of the points were identified, targets of sufficient size to guarantee their visibility in the lowest elevation of the pit even in the highest flights were positioned there. Once the control points were positioned, flight plans were defined to ensure that the entire pit was being overflown and that all control points were visible. Six flights were done from two different apps, the Pix4D and Drone Deploy, where similar grids were used and heights of 60 (sixty), 80 (eighty) and 100 (hundred) meters were considered, with takeoff near the point "Base". The parameters established for the overlap were $70 \%$ longitudinally and $30 \%$ laterally. From the images taken by the UAV, Digital Surface Models of the pit were built through the Agisoft Photoscan software for each flight plan executed. The stages and parameters selected for generation of these models are described in Table I. 


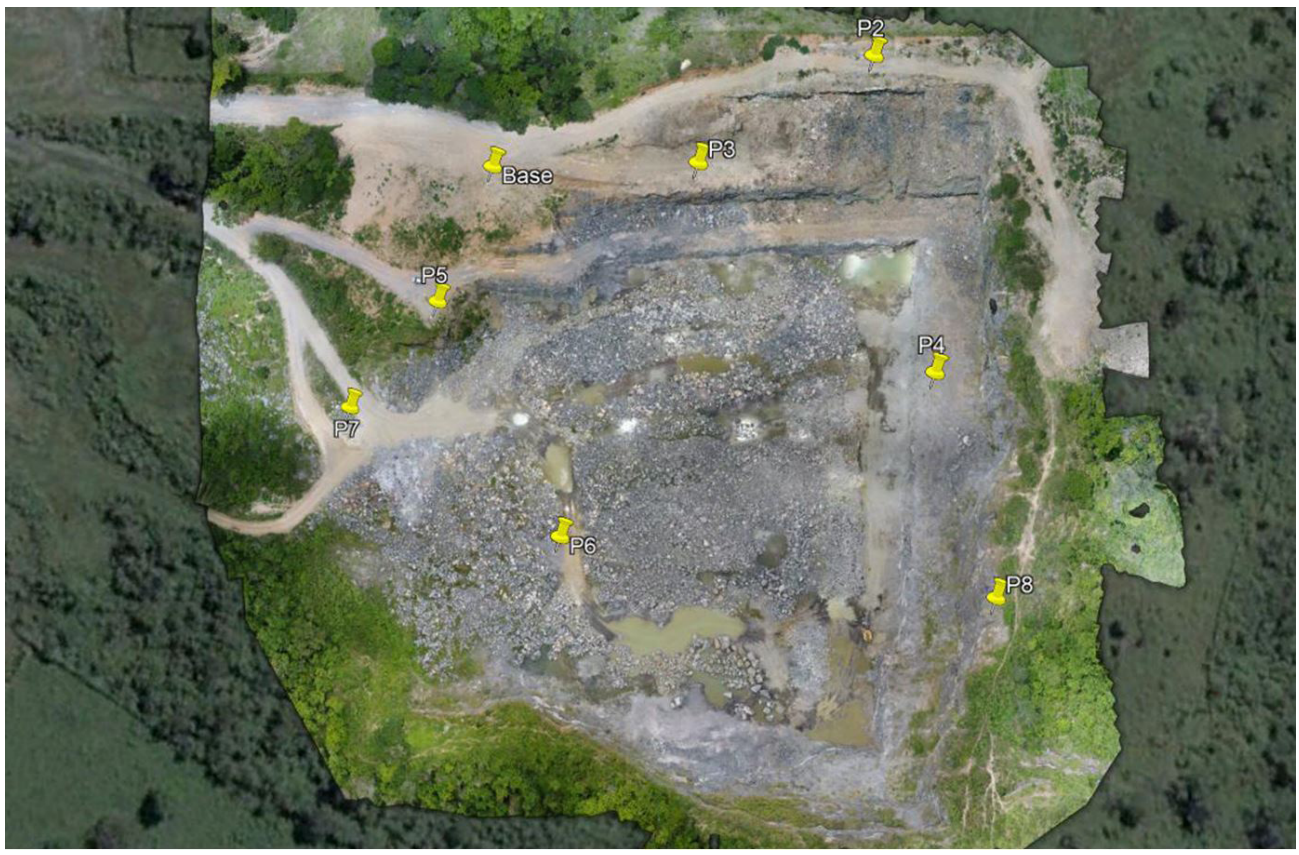

Figure I. Location of control points.

Table I. Stages necessary to obtain models in Agisoft Photoscan

\begin{tabular}{cc}
\hline Stages & Parameters \\
\hline Alignment of images & Highest \\
Dense cloud generation & High - Aggressive \\
Model building & Arbitrary - Dense cloud - Average \\
Texture composition & Generic - Mosaic \\
Digital Elevation Model (DEM) construction & WGS 84/UTM 25S - Dense cloud \\
Ortomosaic construction & DEM - Mosaic \\
\hline
\end{tabular}

In order to provide the correct georeferencing of the models, the photos position were corrected from the points located in the pit, while those that effectively reposition the photos are considered as control points, and those used to evaluate the error produced in this displacement are called check points. This procedure consists of a manual displacement of the reference points to the markers present in some photos, followed by updating the positioning of all the photos after the execution of this correction, thus ensuring the georeferencing of all the data. Among the six models produced, the one that presented the least overall error after this operation was selected.

As validation of the model, the differences of heights between berms in certain places of the pit, measured in a file containing contour lines representing the DSM, were compared with data obtained in the field using a measuring tape.

\subsection{Methods Comparison}

In order to compare the fidelity of the models, the contour lines of these models (produced by different methods) were overlapped on the orthomosaic of the pit.
The theoretical widths and those presented by the models between the foot and the projection of the crest of several slopes in different points were compared, where the maximum and minimum differences presented, the standard deviation and the variance were verified for each model.

\section{RESULTS AND DISCUSSION}

In this section were present the results obtained through the conventional methodology, the results obtained through UAV flights and subsequent terrain modeling, the validation of the best model obtained through flight data and the comparison between the two methodologies.

\section{I Planimetric Survey by Total Station and Open Pit Model Drawing}

Table 2 shows the three points used as basis for the construction of the pit model in the AutoCad 2014 software. Figure 2 shows the result of the model generated by the conventional method, and it is possible to observe the base points used. 


\subsection{Planimetric Survey by UAV Flight and Open Pit Model Generation}

The coordinates of the points collected through the high-precision geodesic GPS are shown in Table 3 . The points P2 to P8 were corrected as a function of the base point, which presented an error of less than $2 \mathrm{~cm}$.

The correct georeferencing of the photos considered, among these eight points, four control points and four checkpoints. Table 4 presents the errors attributed to each group.

Table 2. Easting and northing coordinates of control points (Datum: SIRGAS 2000)

\begin{tabular}{ccc}
\hline Points & Easting & Northing \\
\hline PI & $255,078.528$ & $9,101,579.112$ \\
P2 & $255,121.991$ & $9,101,545.005$ \\
P3 & $255,081.030$ & $9,101,559.388$ \\
\hline
\end{tabular}

Table 3. Easting and northing coordinates of control points (Datum: SIRGAS 2000)

\begin{tabular}{ccc}
\hline Points & Easting & Northing \\
\hline Base & $255,367.185$ & $9,101,686.743$ \\
P2 & $255,472.480$ & $9,101,743.337$ \\
P3 & $255,428.854$ & $9,101,700.135$ \\
P4 & $255,512.627$ & $9,101,655.752$ \\
P5 & $255,359.364$ & $9,101,643.037$ \\
P6 & $255,414.595$ & $9,101,581.115$ \\
P7 & $255,338.416$ & $9,101,604.431$ \\
P8 & $255,547.034$ & $9,101,595.501$ \\
\hline
\end{tabular}

After modeling of the data obtained on six flights, it was verified that the models produced from the Pix4D at 60 and 100 meters in height, besides the one produced by the Drone Deploy at 60 meters, presented faults in its construction, characterized by empty spaces that were not sampled during the flight, being elected for discard. The 60 meter flight could not get details of the upper reaches of the pit, while the 100 meter flight through Pix4D was unable to get in detail some slopes of the berms because the area was covered with fewer number of photos. The model constructed at 60 meter flight by Drone Deploy was consistent due to the fact that it performs at the end of each flight, when the 3D mode is active, a scan perimeter of the plane directed to the center.

From the error report produced by Agisoft Photoscan, the model presented in the Figure 3 produced from the flight with the Drone Deploy at 80 meters in height was selected, since it presented the smallest average error among the others, in addition to having the lowest error in the $\mathbf{z}$ axis (Table 5), which will be used as parameter for the validation of the model.

\subsection{Validation of the Best Model Obtained through UAV Flight}

A file was evaluated in which the contour lines are $0.25 \mathrm{~m}$ away from each other in an attempt to give greater precision to the checking of the feet and crests of the slopes. The form selected to validate the model was the verification of distances found "in loco" with that found in the DSM using a measuring tape. Figure 4 shows the bands where

Table 4. Description of error attached to Ground Control Points and Check Points

\begin{tabular}{ccccccc}
\hline Point Classes & Number Points & $\begin{array}{c}\mathbf{X} \text { axis error } \\
(\mathbf{m})\end{array}$ & $\begin{array}{c}\mathbf{Y} \text { axis error } \\
(\mathbf{m})\end{array}$ & $\begin{array}{c}\mathbf{Z} \text { axis error } \\
(\mathbf{m})\end{array}$ & $\begin{array}{c}\mathbf{X Y} \text { plane } \\
\text { error }(\mathbf{m})\end{array}$ & $\begin{array}{c}\text { Global error } \\
(\mathbf{m})\end{array}$ \\
\hline Ground Control Points & 4 & 0.173 & 0.103 & 0.072 & 0.201 & 0.214 \\
Check Points & 4 & 0.389 & 0.410 & 1.920 & 0.565 & 2.002 \\
\hline
\end{tabular}

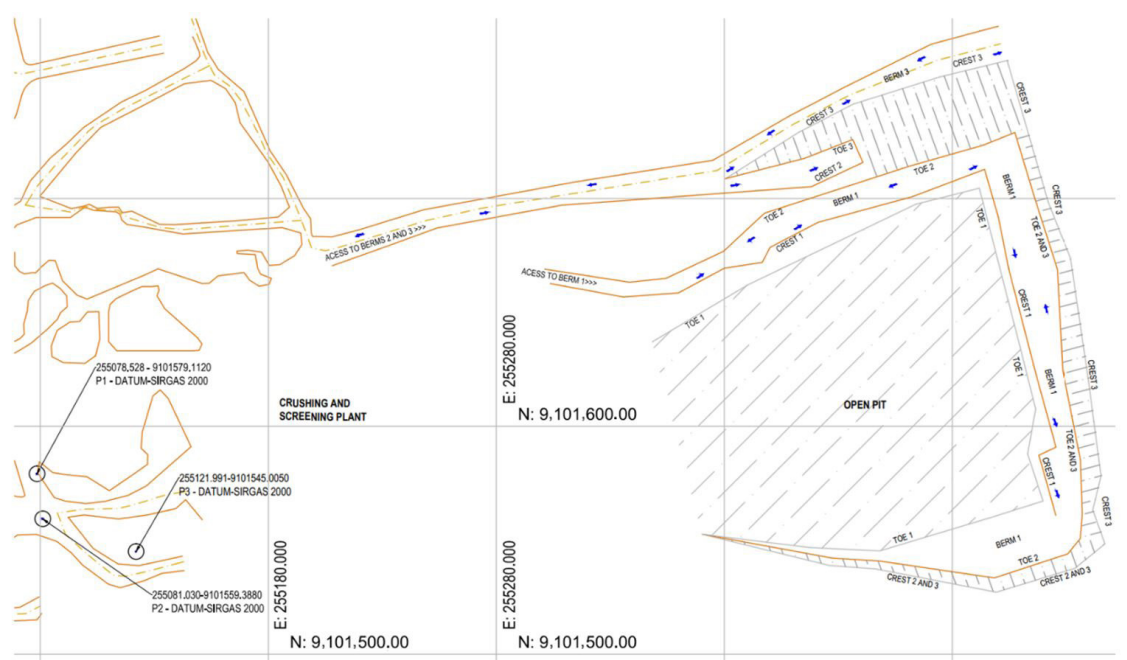

Figure 2. Planimetric model of the open pit developed from conventional methodology. 
the evaluations were performed, while Table 6 presents the comparison between the heights obtained through the measuring tape and the model, verified through the software Datamine Studio 3. A standard deviation of 0.35 meters and a variance of 0.13 meters were verified, which, when considering the imprecise positioning of the evaluation and the large masses and distances represented by a pit, validate the model as satisfactory for the analysis of the mining.

Table 5. Description of error attached to different models

\begin{tabular}{cccccc}
\hline Model & $\mathbf{X}$ axis error $(\mathbf{m})$ & $\mathbf{Y}$ axis error $(\mathbf{m})$ & $\mathbf{Z}$ axis error $(\mathbf{m})$ & $\mathbf{X Y}$ plane error $(\mathbf{m})$ & $\mathbf{G l o b a l}$ error $(\mathbf{m})$ \\
\hline Pix4D 80 m model & 4.263 & 3.653 & 13.246 & 5.614 & 14.386 \\
Drone Deploy 80 m model & 2.327 & 2.011 & 5.357 & 3.076 & 6.177 \\
Drone Deploy 100 m model & 1.149 & 2.645 & 6.529 & 2.884 & 7.138 \\
\hline
\end{tabular}

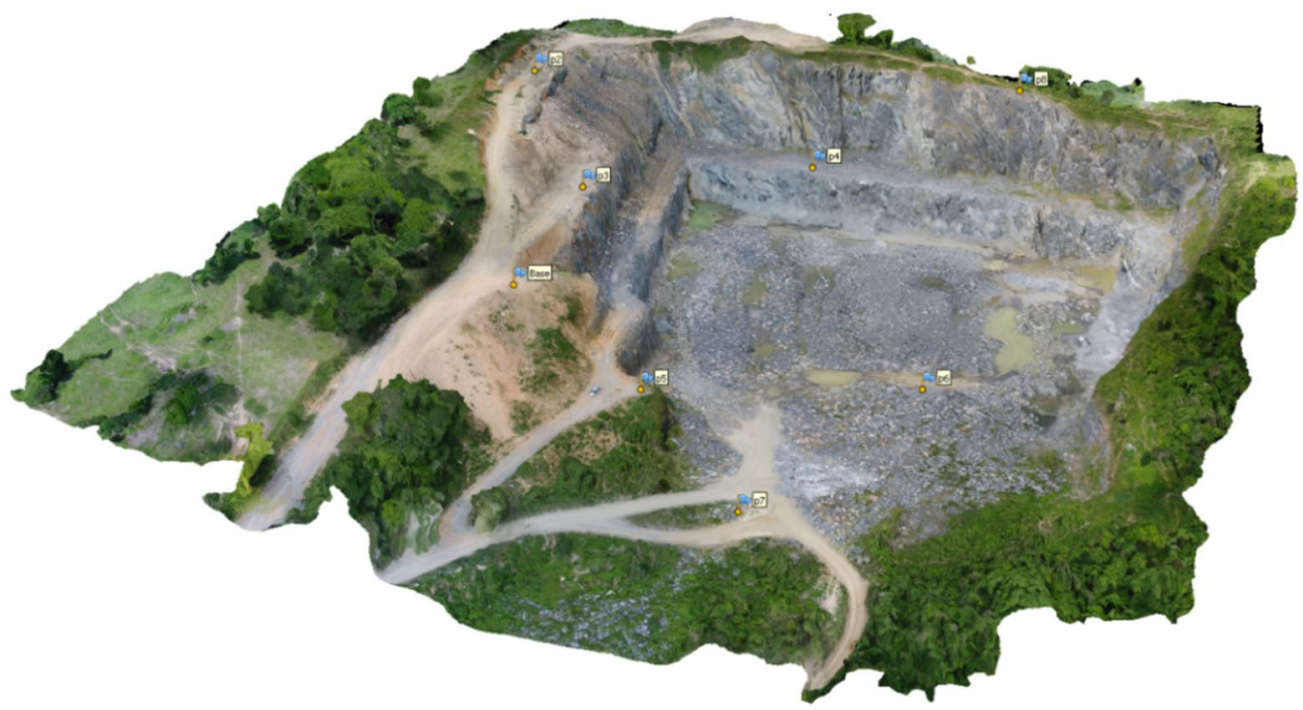

Figure 3. Digital Terrain Model (DTM) obtained by Drone Deploy from 80 meters height UAV flight.



Figure 4. Slopes heights measured "in loco" (yellow) and verified in the model through Datamine Studio 3 (green). 


\subsection{Comparison of Models Produced by Different Methodologies}

The contour lines produced in Agisoft PhotoScan have the limitation of not having precise definition of the foot and crest of the slopes, so that they must be adjusted manually in CAD software for a better definition of the limits of the slopes and berms, according to Figure 5. From this adjustment it was possible to overlap the results obtained with those provided by the planimetric model executed through the conventional methodology, as can be seen in Figure 6 .

Through visual evaluation it was possible to verify that the model obtained from the conventional survey showed an inferior result than the one produced through

Table 6. Heights of the slopes measured used as reference and the ones estimated in the model, followed by the differences between both

\begin{tabular}{cccccccccc}
\hline Slopes & A & B & C & D & E & F & G & H & I \\
\hline Model height & 13.25 & 18.25 & 13.75 & 18.00 & 17.75 & 14.00 & 13.75 & 15.00 & 15.25 \\
Reference height & 13.90 & 19.00 & 14.70 & 18.00 & 18.00 & 14.10 & 14.00 & 15.00 & 15.90 \\
Difference & 0.65 & 0.75 & 0.95 & 0.00 & 0.25 & 0.10 & 0.25 & 0.00 & 0.65 \\
\hline
\end{tabular}

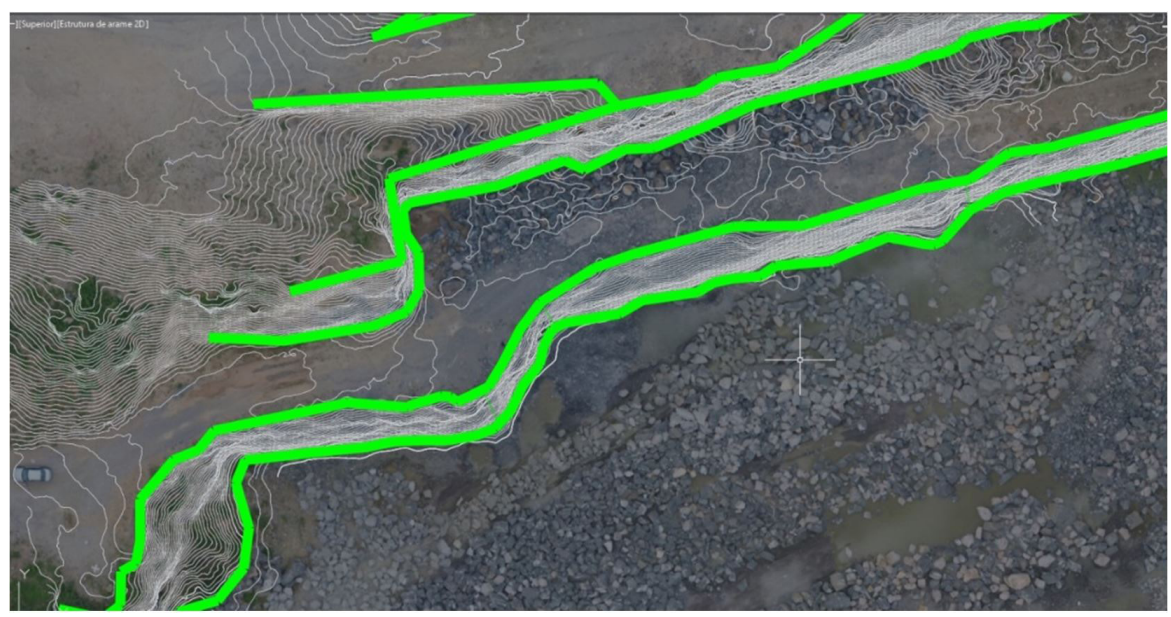

Figure 5. Drawing of slopes crests and feet from contours and orthomosaics.

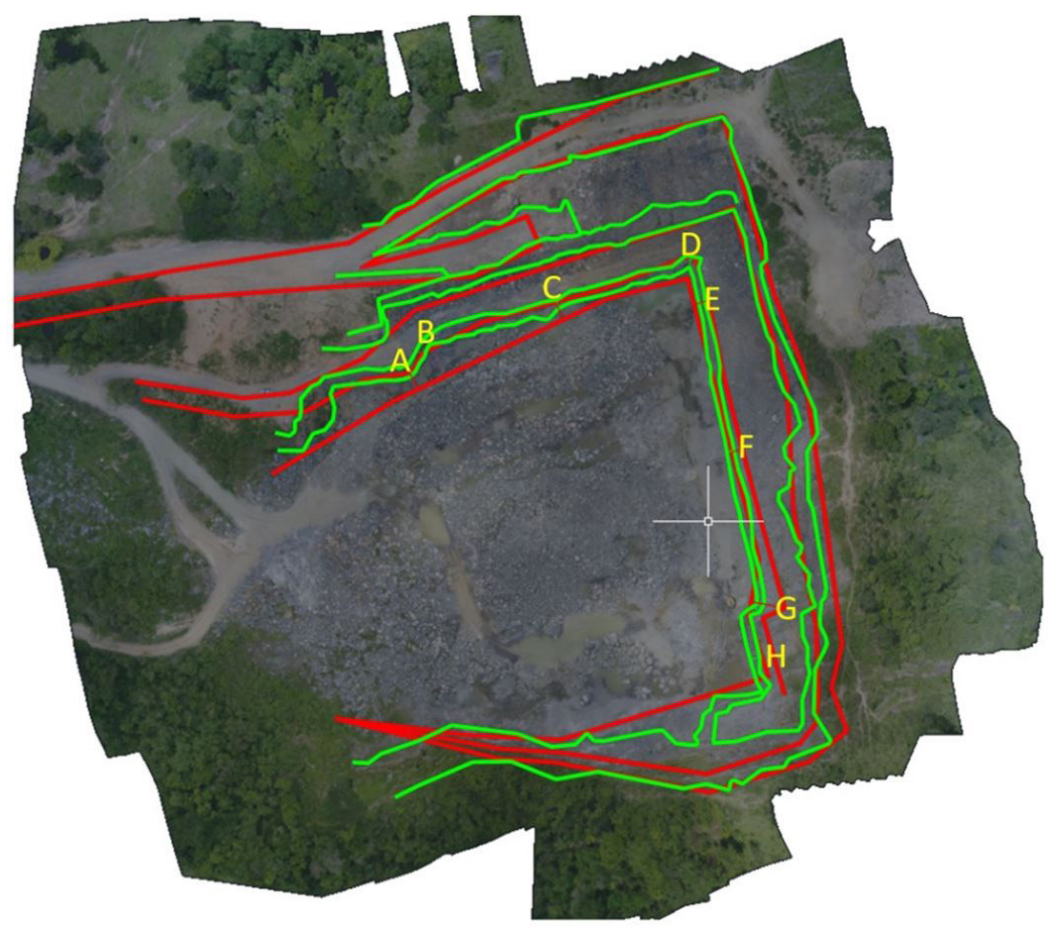

Figure 6. Overlap on AutoCad of berms obtained through UAV (green) and through total station (red) over orthomosaic. 
UAV flight, especially in the slope feet, where the distance between the reference line and the foot of the orthomosaic is unreal in some places. The access roads also lack in details and present displacement of the real position. Besides the displacement of most of the lines, which was probably generated by the difficulty that the team found in walking through certain regions, it is possible to realize that they are represented as great straight lines, due to an insufficient number of points collected, making it more distant to reality. As for the planimetric model produced through UAV flight, it is possible to verify a greater level of detail on crests and feet of the slopes, presenting shape and distances more coherent with the reality than that obtained through the conventional methodology.

Considering that the theoretical dip of the pit slopes is equivalent to $10^{\circ}$, and there may be a variation due to the sliding of wedges present in the structural geology, it was considered that these could have values between $7^{\circ}$ and $15^{\circ}$.
Through a trigonometric relation it is possible to calculate the maximum and minimum distances between the projection of the crest of the slope in the ground and its foot for each bench. For calculation purposes and due to the difficulty in knowing precisely the aspect of the bench slopes, it was considered that these were flat, not having overbreak (would decrease the value of minimum and of maximum) or underbrake (would increase the value of minimum and of maximum), as shown in Figure 7.

Table 7 shows the heights verified using measuring tape on the points identified from $\mathrm{A}$ to $\mathrm{H}$ in Figure 6, where the minimum and maximum widths were assigned to each according to the trigonometric relation and the stipulated angles. Table 8 shows in columns 2 and 5 the width measured in the models using CAD software, together with the differences between the reference values of each methodology, the minimum (columns 3 and 6) and theoretical maximums (columns 4 and 7) described in Table 7.
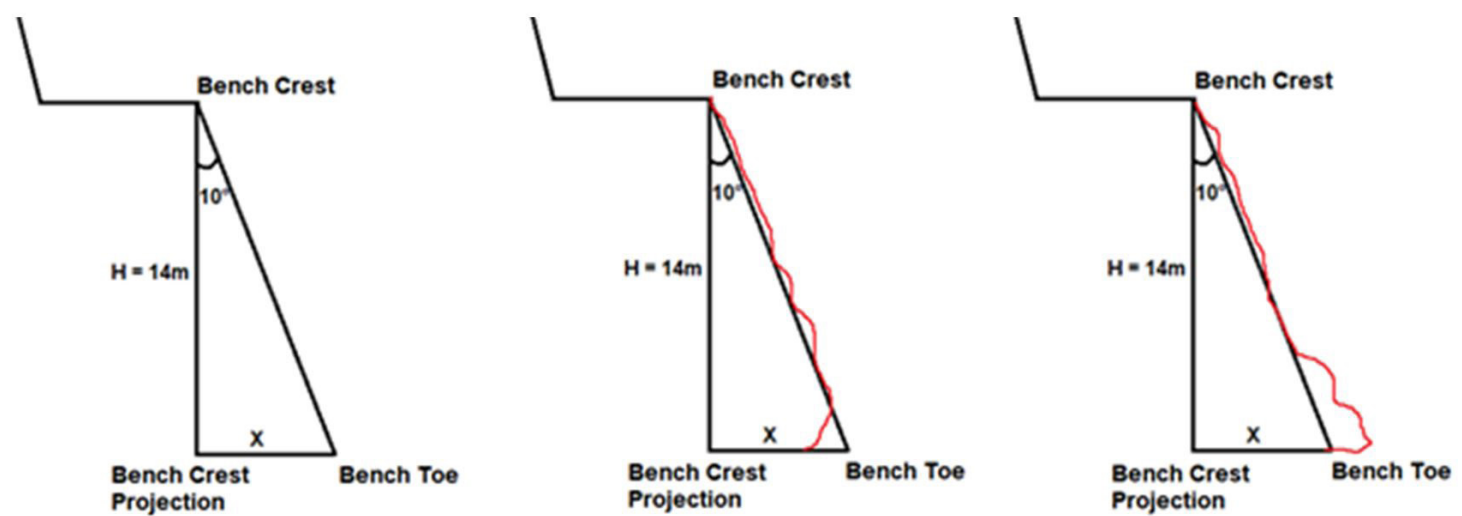

Figure 7. Projection of bench crest on the level of the toe and examples of overbreak and underbreak.

Table 7. Minimum and maximum width considering each bench height and the limits of each angle

\begin{tabular}{cccc}
\hline Bench Position & Height $(\mathbf{m})$ & Min. Width $(\mathbf{m})$ & Max. Width (m) \\
\hline A & 13.90 & 1.71 & 3.725 \\
B & 13.90 & 1.71 & 3.725 \\
C & 14.70 & 1.80 & 3.940 \\
D & 14.00 & 1.72 & 3.752 \\
E & 14.00 & 1.72 & 3.752 \\
F & 15.00 & 1.84 & 4.020 \\
G & 15.90 & 1.95 & 4.261 \\
H & 15.90 & 1.95 & 4.261 \\
\hline
\end{tabular}

Table 8. Width measured in each methodology and the differences between the theoretical minimum and maximum widths and the allowed for each methodology

\begin{tabular}{ccccccc}
\hline Bench Position & $\begin{array}{c}\text { Widht Total } \\
\text { Station }(\mathbf{m})\end{array}$ & $\begin{array}{c}\text { Min. Difference } \\
(\mathbf{m})\end{array}$ & $\begin{array}{c}\text { Max. Difference } \\
(\mathbf{m})\end{array}$ & $\begin{array}{c}\text { Widht UAV } \\
(\mathbf{m})\end{array}$ & $\begin{array}{c}\text { Min. Difference } \\
(\mathbf{m})\end{array}$ & $\begin{array}{c}\text { Max. Difference } \\
(\mathbf{m})\end{array}$ \\
\hline A & 6.30 & 4.593 & 2.575 & 4.02 & 2.313 & 0.295 \\
B & 10.67 & 8.963 & 6.945 & 3.17 & 1.463 & -0.555 \\
C & 6.67 & 4.865 & 2.730 & 3.20 & 1.395 & -0.740 \\
D & 8.58 & 6.861 & 4.828 & 3.71 & 1.991 & -0.042 \\
E & 4.77 & 3.051 & 1.018 & 2.17 & 0.451 & -1.582 \\
F & 3.74 & 1.898 & -0.280 & 2.62 & 0.778 & -1.400 \\
G & 11.73 & 9.778 & 7.469 & 2.88 & 0.928 & -1.381 \\
H & 4.02 & 2.068 & -0.241 & 3.37 & 1.418 & -0.891 \\
\hline
\end{tabular}


The standard deviations verified for the minimum and maximum differences of the survey through total station were 3.016 and 3.028 , respectively, whereas the ones presented for the model obtained by flight of UAV were 0.618 and 0.671 , respectively, results significantly superior to the first ones. The verified variances for the minimum and maximum differences of the total station survey were, in turn, 9.094 and 9.169 , while those obtained by UAV flight were 0.382 and 0.450 , representing an even greater discrepancy than the standard deviation.

\section{CONCLUSIONS}

Among the six models produced by UAV flights, considering three different heights and two apps for definition of the flight plan (Pix4D and Drone Deploy), three were eliminated due of the inconsistencies related to the height of the flights in combination with the methodology of each app. Among the three elected as likely, the one produced through Drone Deploy with 80 meters high from the "Base" point was selected, since it presented smaller errors in the $z$ axis and global. From this definition it was possible to modeling the pit in the Agisoft PhotoScan software and validate the heights of some bench points using measure tape "in loco" and compare it to model benchs through Datamine Studio 3. It was verified the validity of the model for the proposed objective of updating the advance of the exploitation from the production of a planimetric model of a pit, where the standard deviation obtained was of the order of 0.35 meters and the variance of the order of 0.13 meters.

When the overlapping of the models produced using total station and UAV survey, it was possible to visually identify that the pit presented greater coherence and berms and slopes better delineated in the model obtained from the UAV flight. Regarding the measurement of slope widths in CAD software, when considering the possibility of slopes having angles between $7^{\circ}$ and $15^{\circ}$, it was verified that the values presented by the model produced using total station were unlikely from the maximum and the minimum possible for the angles considered. The standard deviations were of the order of 3.016 and 3.028 and the variances were of the order of 9.094 and 9.169 , while the standard deviations of the model produced using UAV flight were of the order of 0.618 and $0.67 \mathrm{I}$ and the variances were 0.382 and 0.450 , what elects the second model as more coherent.

This discrepancy in results is likely to be intrinsic to the applied methodologies. Conventional topography allows the collection of few slope crests and feet data, over-smoothing the intervals between points with the creation of straight lines, as well as the team's difficulty in accessing certain points on the edges, impairing the correct positioning of points. The flights made with UAV, on the other hand, collect certain number of photos that are transformed into a greater number of points, which allows the creation of a more accurate model and increase the level of detail, ensuring the superiority of the method and its applicability to the verification of the advance of exploitation in open pit mines through the production of planimetric model.

\section{REFERENCES}

I Carneiro M, Ferreira RHS, Quadros TFP, Kautzmann RM. Geração de modelo digital de terreno por restituição aerofotogramétrica com apoio de Veículo Aéreo Não Tripulado de pequeno porte: estudo de caso na pedreira da empresa Incopel - Estância Velha/RS. Tecnologica em Metalurgia, Materiais e Mineração. 20 I8;I5(3):3 I4-32I. http:// dx.doi.org/I0.4322/2I76-I523.138I.

2 Jorge LAC. Metodologia para utilização de aeromodelos em monitoramento aéreo: análise de imagens. São Carlos: EMBRAPA Instrumentação Agropecuária; 2003.

3 Schenck T. Introduction to photogrammetry. Columbus: The Ohio State University; 2005 [cited 2018 Aug 27]. Available at: http://www.mat.uc.pt/ gil/downloads/IntroPhoto.pdf.

4 Brito J, Coelho L. Fotogrametria digital. Rio de Janeiro: Instituto Militar de Engenharia; 2002.

5 Correia JML No. Avaliação entre a metodologia convencional de modelagem de cavas lavradas em bancadas múltiplas e através do uso de VANT's [monografia]. Recife: Universidade Federal de Pernambuco; 2018.

6 Eisenbeiss $\mathrm{H}$. The potential of unmanned aerial vehicles for mapping. In: Pritsch D, editor. Phogrammetric week 20I I. Stuttgart: Institut fur Photogrammetrie; 20I I. p. I35-I44.

Received: 19 Jan. 2019

Accepted: 9 June. 2019 